\title{
Experimental Investigation of Concrete Filled PVC Tube Columns Confined By Plain PVC Socket
}

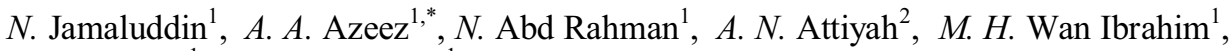 \\ $N$. Mohamad ${ }^{1}$, and $S . H$. Adnan ${ }^{1}$ \\ ${ }^{1}$ Jamilus Research Center, Universiti Tun Hussein Onn Malaysia, 86400 Batu Pahat, Johor, Malaysia \\ ${ }^{2}$ Faculty of Civil Engineering, University of Kufa, P.O. Box (21), Najaf Governorate, Iraq
}

\begin{abstract}
This paper presents results of an experimental study for concrete column filled poly vinyl chloride (PVC) tubes confined by plain socket with $5.8 \& 6.8 \mathrm{~mm}$ thicknesses, $102 \mathrm{~mm}$ diameter and $100 \mathrm{~mm}$ depth. The total of five concrete filled columns using PVC tubes (CFT PVC) was tested to investigate the columns' behaviour. The column is 700 $\mathrm{mm}$ height, $100 \mathrm{~mm}$ external diameter and $3.5 \mathrm{~mm}$ tube thickness with different thickness of plain socket. The results presented include maximum axial load, plain socket confinement effect, the mode of failure, and lateral PVC strain. The axial load enhancement of PVC-concrete columns confined using plain socket shows an increment of $21.3 \%$ up to $55.2 \%$ and axial strain from $21 \%$ to $40 \%$ compared with displacement for control composite columns at $192 \mathrm{kN}$ ultimate load.
\end{abstract}

\section{Introduction}

In building construction, the merits of a structure are based on factors such as availability, structural strength, durability, and workability. The properties of the structure materials may differ from each other and there is no single material that can fulfill all structural requirements which resulted in the application of composite structures. Composite columns, particularly composite concrete filled steel tube (CFST) columns, are increasingly used for high-rise building structures, owing to the advantage of combined characteristics of the steel and concrete materials.

PVC has advantages such as low cost, lightweight and is easy to handle and install. It is not affected by corrosion or other forms of degradation; therefore, it is used as an alternative to the metal in many applications where corrosion can compromise functionality and increase maintenance cost. However, the study of concrete-filled PVC tube (CF-PVCT) composite columns are limited even though its advantages are many. The PVC tube does not only protect the core concrete from the corrosion of the atrocious environment, but it is the cheapest material and locally available in abundance. The development of the CFT column using this material could be an achievement for the local construction industries.

* Corresponding author: alyaaabdulrazzaq@yahoo.com 
Steel and concrete are the common materials used in the composite CFT columns. The CFT columns are known due to their superior of strength with the ability to withstand the load imposed during the event of Kobe earthquake when their ability accidently encountered. The CFT columns have many constructional advantages, such as high energy absorption, economical formwork and high ductility. These advantages are contributed by the effectively confined concrete core; thus, the realistic prediction of the capacity of these columns must consider the confinement effect provided by the steel tube.

An attempts to use composite columns with plastic tubes can be traced back from the work done by Kurt [1] and recently this column type has gained attention from several researchers $[2,3]$. One of the advantages of PVC tube is, being a non-conductor of electricity and immune to the electrochemical based corrosion process. However, not only fewer studies were found on the CFT columns using PVC tubes, its successful design and application requires adequate recognition of its more complex stress/strain and stress/fracture behavior.

The tubes located at the circumferential contribute to strength enhancement of the CFT column. As for concrete filled steel tube columns, CFST, the steel tube not only provide permanent formwork for the concrete core, but its superior strength was contributed from the confinement effect of the steel tube itself that may be expected due to its material properties. Other than that study by Marzouck and Sennah [4] the slenderness ratio also contributes to the columns' strength. Gupta and Verma [5] carried out a study on the length to diameter ratio $(\mathrm{D} / \mathrm{t})$ columns effect on such columns. As for PVC, it does not exhibit the simple proportionality between stress and strain that is characteristic of steel material, the PVC capacity to resist fracture is reduced as duration of loading is increased. In addition the PVC tube having a non-stick inner surface resulted in lower friction factors and expected to affect the lateral confining pressure on the concrete core.

In this study, plain sockets were attached to PVC CFT columns with the attention to strengthen such columns. The contribution of the plain socket in confinement effect, load carrying capacity, ductility and durability of the column were investigated.

\section{Experimental Details}

\subsection{Generals}

Five specimens of the PVC CFT columns were tested to failure. There were a control specimen, $\mathrm{C} 1$ and $100 \mathrm{~mm}$ height of plain sockets with different thickness of $5.8 \mathrm{~mm}$ and $6.8 \mathrm{~mm}$ (Fig. 1) were attached to the rest of the columns (CS1, CS2, CS3 and CS4). Table 1 tabulated the details of the column specimens.

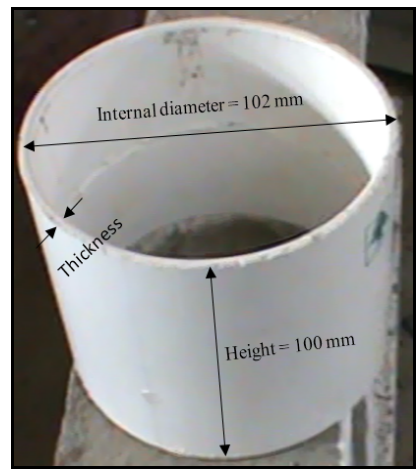

Fig. 1. Details of plain socket 
Table 1. Specimens details

\begin{tabular}{|c|c|c|c|c|}
\hline Mix ID & $\begin{array}{l}\text { Tube Length } \\
\text { (m) }\end{array}$ & $\begin{array}{l}\text { Diameter } \\
(\mathbf{m m})\end{array}$ & $\begin{array}{c}\text { Thickness } \\
\text { (mm) }\end{array}$ & $\begin{array}{r}\text { Plain socket } \\
\text { thickness }(\mathrm{mm})\end{array}$ \\
\hline $\mathrm{C} 1$ & \multirow{5}{*}{700} & \multirow{5}{*}{100} & \multirow{5}{*}{3.5} & - \\
\hline $\mathrm{CS} 1$ & & & & 5.8 \\
\hline $\mathrm{CS} 2$ & & & & 5.8 \\
\hline $\mathrm{CS} 3$ & & & & 6.8 \\
\hline CS4 & & & & 6.8 \\
\hline
\end{tabular}

\subsection{Materials}

\subsubsection{Poly Vinyl Chloride (PVC) Tube}

The typical physical properties of PVC tubes are shown in Table 2. The PVC tubes were cut into several pieces for the preparation of tensile coupon specimens. The material properties of the PVC element were accordingly determined from mechanical testing on PVC coupons shape as in Fig. 2. The behaviour of PVC described through the stress-strain relationship from the test and the stress-strain graphs are plotted in Fig. 3 with the average of ultimate tensile stress for these coupons is $49.4 \mathrm{MPa}$.

Table 2. Physical properties of PVC pipes

\begin{tabular}{|c|c|}
\hline Parameter & Value \\
\hline Relative Density & $1.42-1.48$ \\
Elastic tensile modulus & $3.0-3.3 \mathrm{GPa}$ \\
Poisson ratio & 0.4 \\
Ultimate tensile strength & $52 \mathrm{MPa}$ \\
Elongation at break & $50-80 \%$ \\
Elastic flexural modulus & $2.7-3.0 \mathrm{GPa}$ \\
\hline
\end{tabular}

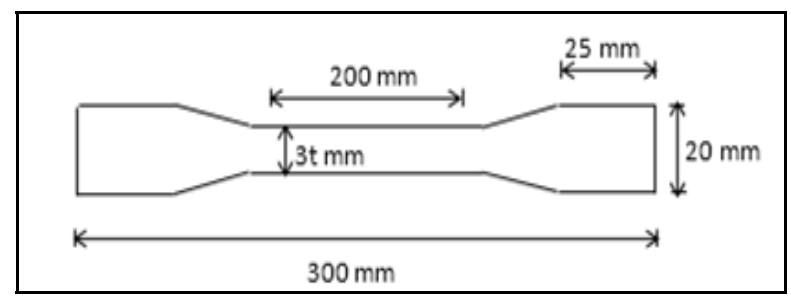

Fig. 2. Coupon scheme

Table 3. Coupon mechanical properties

\begin{tabular}{|l|c|}
\hline \multicolumn{1}{|c|}{ Property } & Value \\
\hline Average Modulus of elasticity (MPa) & 2770 \\
\hline Average ultimate tensile stress (MPa) & 49.4 \\
\hline
\end{tabular}




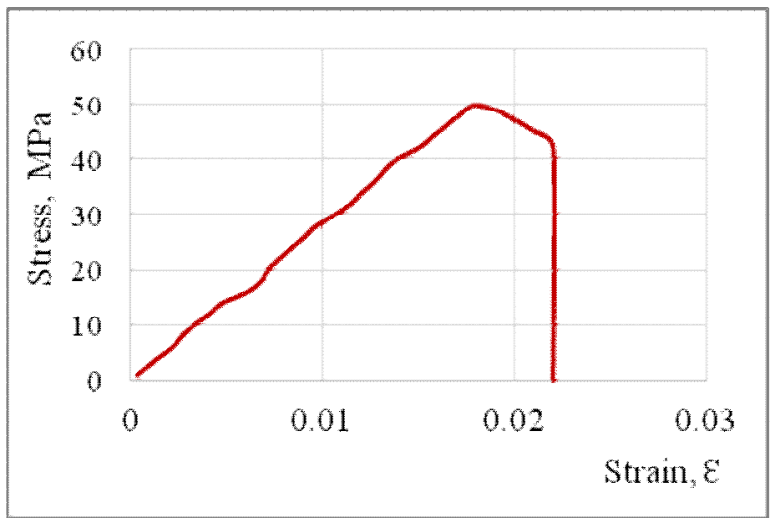

Fig. 3. Stress- strain curve

\subsubsection{Properties of concrete}

Ready mix concrete with targeted compressive strength of $20 \mathrm{MPa}$ was considered. The average compressive strength results obtained from $150 \mathrm{~mm}$ cubes and $100 \times 200 \mathrm{~mm}$ cylinders at 28-days of curing are 26.3 MPa and 21.6 MPa, respectively.

\subsection{Preparation of the column specimens}

The PVC tubes with thickness of $3.5 \mathrm{~mm}$ and a diameter of $100 \mathrm{~mm}$ were cut to the length of $700 \mathrm{~mm}$ as shown in Fig. 4. The tubes were positioned vertically, fixed on the laboratory floor and filled with concrete in approximately $10 \mathrm{~cm}$ layers, and each layer was compacted by a steel rod. To prevent the leakage of cement paste from the bottom of the PVC tube, it was covered with nylon. After the tube was filled, the top surface was flush in order to ensure the loading was evenly distributed across the cross section (Fig. 5). The columns were then covered with Hessian and plastic cover for curing. The specimens were moistened with water every day after 24 hours after casting.
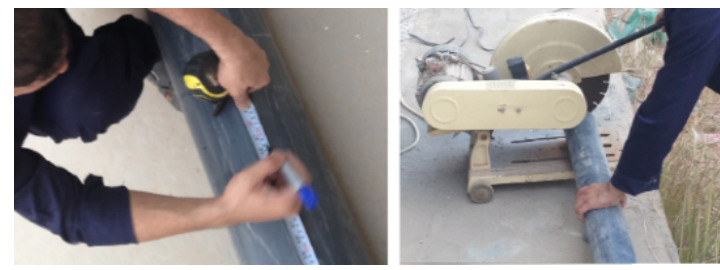

Fig. 4. Preparation of specimens
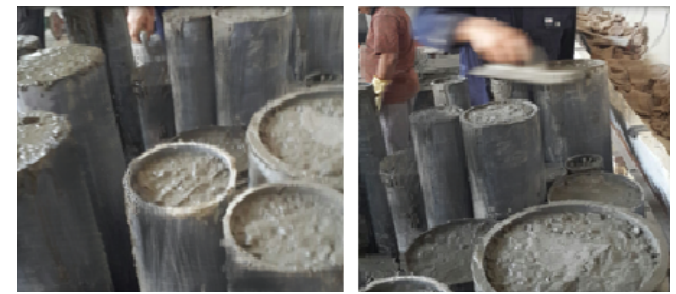

Fig. 5. Casting the composite columns 


\subsection{Test setup and procedure}

All specimens were tested under axial compression using a universal testing machine with a capacity of $1000 \mathrm{kN}$. Surface grinding were performed at the top and bottom specimen to remove surface imperfections and maintain uniformity of loading on the surface (Fig. 6). The column specimens were then positioned at the centre of the testing machine to avoid any eccentricity during the testing. The vertical displacement of the lower movable head of the testing machine was measured in relation to the upper head of the testing machine by a dial gauge with magnetic base. Two strain gauges were located at mid height and two-third from the column supports (Fig. 7).The data of loads and displacements were recorded at regular intervals during the tests. The application of the load was continued until the columns failed.
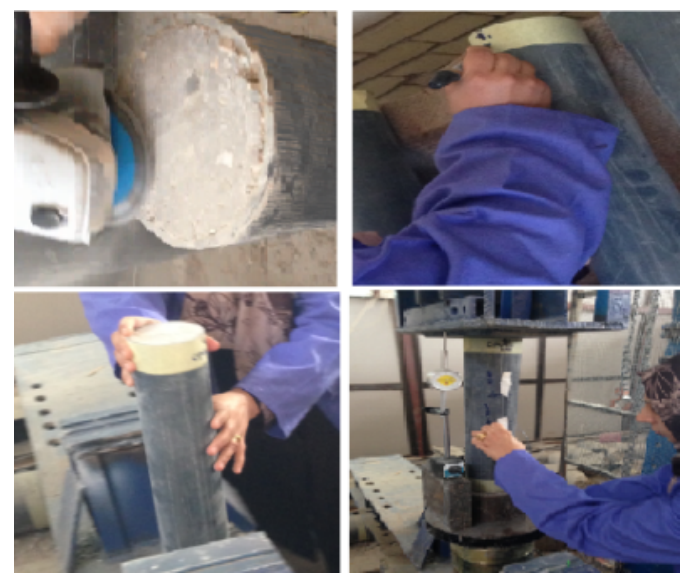

Fig. 6. Preparation of specimens to test

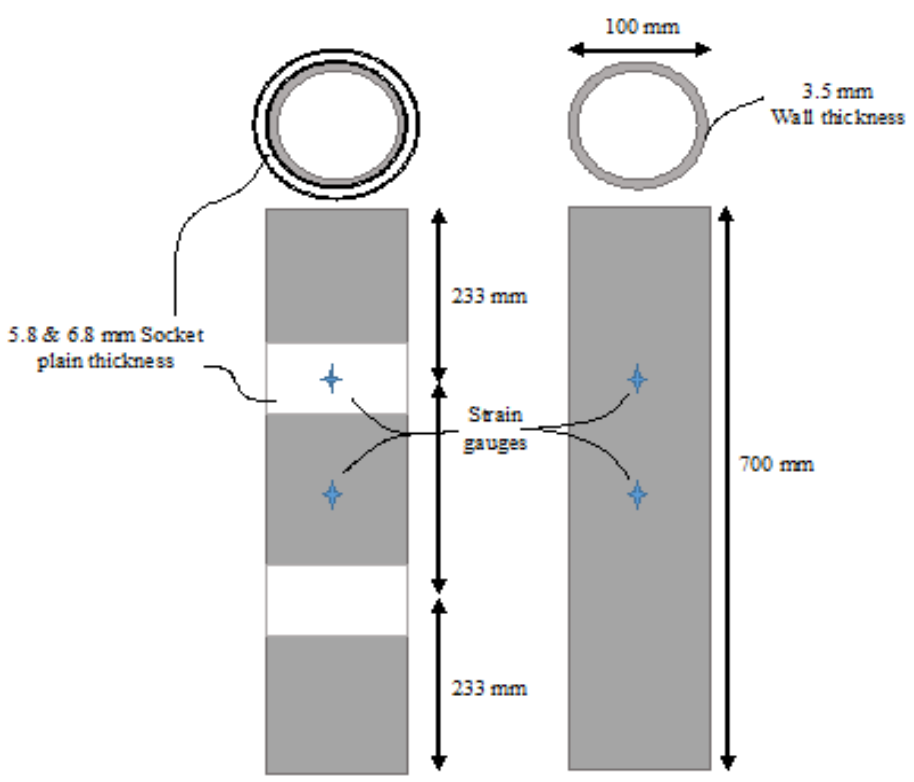

Fig. 7. Schematic diagram of PVC CFT Column 


\section{Results}

\subsection{Column strengths}

Comparison of the ultimate load made between the control specimen of $\mathrm{C} 1$ and PVC CFT columns attached to the plain socket shows the increment range is in between $21 \%$ to $55.2 \%$ (Table 4). This is expected due to the contribution of the plain socket in confining the concrete core. The PVC tube itself causes the development of a triaxial stress field within the confined concrete, constraining it during dilation and thereby increasing the load carrying capacity. Further increment can be seen for columns with the thicker plain socket.

Table 1. Experimental results

\begin{tabular}{|c|c|c|c|c|}
\hline Specimens & $\begin{array}{c}\text { Plain socket } \\
\text { thickness (mm) }\end{array}$ & $\begin{array}{c}\text { Ultimate } \\
\text { load }\end{array}$ & $\begin{array}{c}\text { Enhancement } \\
\mathbf{( \% )}\end{array}$ & $\begin{array}{c}\text { Maximum } \\
\text { displacement (mm) }\end{array}$ \\
\hline C1 & - & 192 & - & 8.5 \\
\hline CS1 & 5.8 & 233 & 21.3 & 9.4 \\
\hline CS2 & 5.8 & 246 & 28.1 & 9.7 \\
\hline CS3 & 6.8 & 291 & 51.5 & 10.5 \\
\hline CS4 & 6.8 & 298 & 55.2 & 10.9 \\
\hline
\end{tabular}

\subsection{Failure modes}

Two types of failure modes were observed in this study; shear failure and outward buckling. For control specimen, $\mathrm{C} 1$ the principal failure was due to the shear failure of the concrete core (Fig. 8). This could be seen from the shape of outward buckling of the PVC tube and the failure in the concrete core after the PVC tube was cut out. At the end of the loading stage of the specimen, the $\mathrm{C} 1$ column was ruptured due to the concrete core crush and the sudden exploded could be heard from the test without warning. On the other hand, cracks were observed to occur in the plain socket for the rest of the columns (CS1, CS2, CS3 and CS4) which can be considered as the warning before the columns' failure. For these columns, the outward buckling was observed to occur near to the top, bottom, and in between the plain socket (Fig. 9).
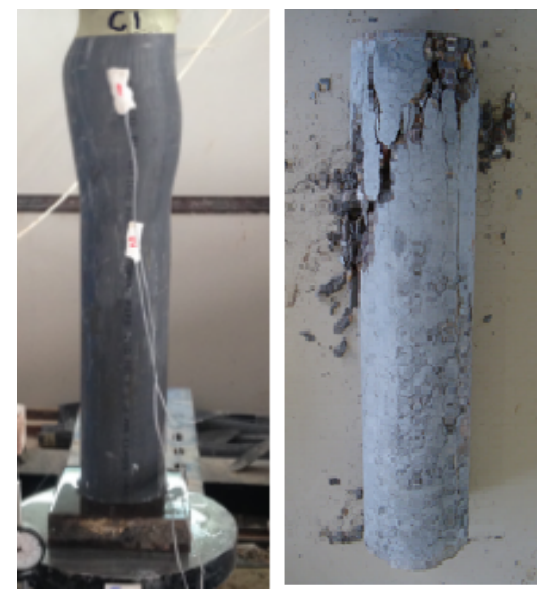

Fig. 8. Specimen $\mathrm{C} 1$ 


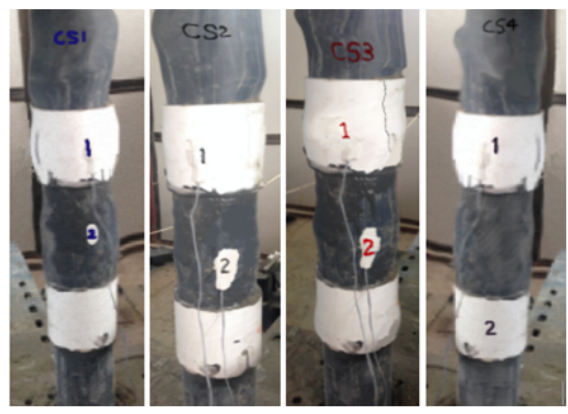

Fig. 9. Failure modes for CFT PVC columns with plain socket

\subsection{Strain behavior of confined PVC-concrete composite columns using plain socket}

The load-lateral strain graphs of the columns is shown in Fig. 10. From all column specimens, the strain ratio of $\varepsilon_{\mathrm{c}} / \varepsilon_{\mathrm{cs}}$ which measured at a two-third column's length is in between $0.77 \%-0.93 \%$, whereas at the columns' mid-height, the strain ratio of $\varepsilon_{\mathrm{c}} / \varepsilon_{\mathrm{cs}}$ is between $0.75 \%-0.93 \%$ where; the $\varepsilon_{\mathrm{c}}$ is a strain on control specimen, $\mathrm{C} 1$ and $\varepsilon_{\mathrm{cs}}$ is the strain for columns with plain socket. From the figure, it can be observed that the columns with plain socket reached higher load at the similar strain of the control specimen which indicate that the plain socket effectively confining the concrete core at the specific location.
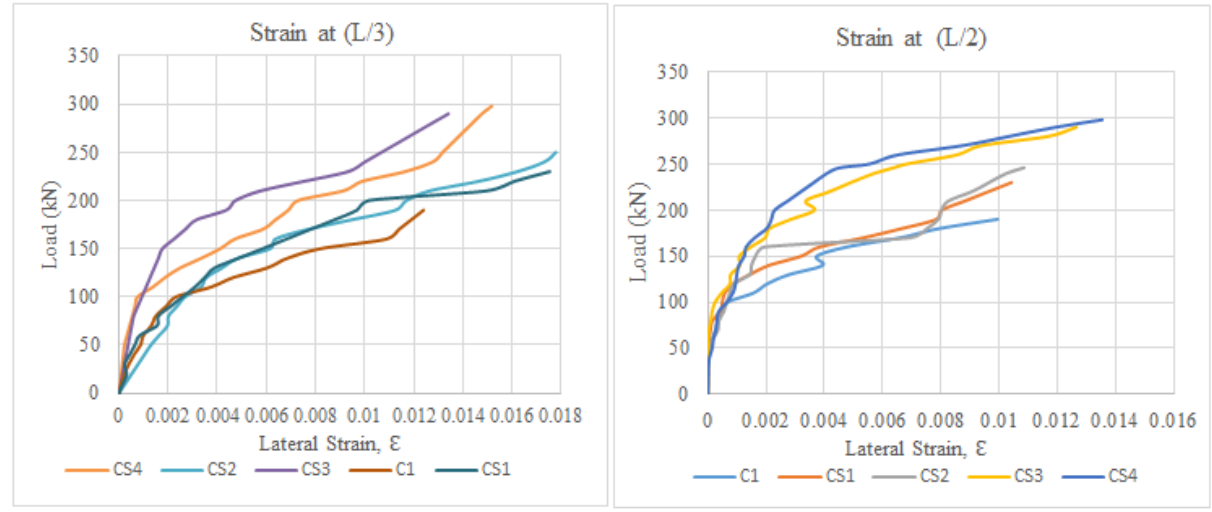

Fig. 10. Lateral strain profile

\section{Conclusions}

This paper reports the results of an experimental program of CFT columns using plasticized polyvinyl (PVC) tubes. From the experimental results, the plastic pipes were found to be effective in confining the concrete core as evidenced by the increased of ultimate loads. The enhancement in axial load due to confinement by using plain sockets of composite columns is substantial and depends on the level of confinement, in which the ultimate load is increased from $21.3 \%$ to $55.2 \%$ of the column without the plain socket. It is also evidence that the columns with plain socket reached higher loads compared to the control specimen at similar strain.

The research reported in this paper is a collaboration between the University Tun Hussein Onn Malaysia and University of Kufa, Iraq who are gratefully acknowledged. 


\section{References}

[1] C.E. Kurt, Concrete filled structural plastic columns, J. of the Structural Division, 104(ASCE 13478 Proc.), 55-63 (1978)

[2] K.G. Naftary, O.O. Walter and N.M. Geoffrey, Compressive strength characteristics of concrete filled plastic tubes short columns, Int. J. of Science and Research, 3(9), 216874 (2014)

[3] C.M. Usha and H. Eramma, Experimental study on concrete filled, unplasticised poly vinyl chloride (UPVC) tubes, Int. J. of Advanced Technology in Engineering and Science, 2(7), 2348 - 7550 (2014)

[4] M. Marzouck and K. Sennah, Concrete-filled PVC tubes as compression members: Composite materials in concrete construction, Proc. of the Int. Congress Challenges of Concrete Construction, 31-38, Scotland, UK, (2002)

[5] P.K Gupta and V.K. Verma, Study of concrete-filled unplasticized poly-vinyl chloride tubes in marine environment, Int. J. of International Journal of Advanced Structural Engineering, 5(1), 1-8 (2013) 